\title{
INDICADORES SOCIOECONÔMICOS CORRELACIONADOS AO PROCESSO DE DESERTIFICAÇÃO NO POLO DE JEREMOABO BAHIA
}

\author{
Clébisson Carvalho Almeida $^{1}$; Elane Fiuza Borges ${ }^{2}$ \\ 1. Bosista PEBIC/FAPESB, Graduando em Geografia, Universidade Estadual de Feira de Santana, e-mail: \\ Clebisson2@gmail.com \\ 2. Orientadora, Departamento de Ciências Humanas e Filosófica, Universidade Estadual de Feira de Santana, \\ e-mail: elaneborges@gmail.com
}

PALAVRAS-CHAVE: Desertificação, IPE, IPS.

\section{INTRODUÇÃO}

O fenômeno da desertificação é um problema de escala mundial, nesse ocorre à perda da capacidade produtiva dos recursos naturais, que é causada principalmente, pela ação antrópica em ambientes naturalmente fragilizados pela ação climática.

Percebe-se que são nessas ASD que se concentram os maiores bolsões de pobreza, os quais não se fundamentam apenas pelos fenômenos naturais, mas também na trajetória histórica dessas áreas. Portanto, o objetivo geral desta pesquisa consistiu em analisar a relação dos indicadores socioeconômicos com o mapa de degradação ambiental no Polo de Jeremoabo e como objetivos específicos construir um banco de dados socioeconômicos a partir da Superintendência de estudos econômicos e sociais da Bahia (SEI), Instituto Brasileiro de Geografia e Estatística (IBGE), entre outros órgãos governamentais; efetuar a tabulação dos dados socioeconômicos; construir uma base de dados em ambiente SIG e em seguida elaborar mapas dos indicadores socioeconômicos do Polo de Jeremoabo (IPE, IPS).

\section{METODOLOGIA}

No sítio eletrônico da SEI foram pesquisados os indicadores sociais e econômicos(Índice de Performance Econômica - IPE e Índice de Performance Social - IPS) do estado da Bahia. Posteriormente, selecionaram-se os indicadores e seus respectivos subindicadores: IPE, composto pelos subíndices INF - Índice de Infraestrutura; IPM - Índice do Produto Municipal; ICE - Índice de conta Corrente e IIF - Índice de Independência Fiscal; IPS composto pelos subíndices INS - Índice do Nível de Saúde; INE - Índice do Nível de Educação, ISB - Índice da Oferta de Serviços Básicos e IMT - Índice do Mercado de trabalho) dos municípios que compõe o Polo Regional de Jeremoabo, referente ao ano de 2010.

Os indicadores econômico (IPE) e social (IPS), foram reclassificados em 4 intervalos de classes, por meio do método quebras naturais (Jenks). Posteriormente, realizou-se a tabulação cruzada com o dado de degradação ambiental e os índices IPE e IPS. Fez-se o cálculo de valores em pixels para porcentagem, a fim de demonstrar a relação entre estes dados.

\section{RESULTADOS E DISCUSSÃO}

Nas áreas de ocorrência de desertificação tem-se associado o mau uso do solo, intensificando este fenômeno, por isso os indicadores econômicos e sociais auxiliam na compreensão das causas e das possíveis consequências do processo de desertificação, que se instala, principalmente, em decorrência da degradação ambiental. As Tabelas 1 e 2 apresentam o resultado da tabulação cruzada entre os dados de degradação ambiental e os índices IPS e IPE. 
Tabela 1. Valores da tabulação de degradação e IPS em porcentagem

\begin{tabular}{|l|l|l|l|l|l|}
\hline \multicolumn{5}{|c|}{ Valores da tabulação de degradação e IPS em porcentagem } \\
\cline { 2 - 7 } Degradação (\%) & $4927-4950$ & $4950-4975$ & $4975-4991$ & $4991-5056$ \\
\hline Baixa degradação & 24 & 38 & 26 & 29 \\
\hline Média degradação & 16 & 28 & 25 & 21 \\
\hline Media alta degradação & 34 & 18 & 31 & 36 \\
\hline Alta degradação & 27 & 16 & 17 & 14 \\
\hline total & \multicolumn{7}{|c|}{100} & \multicolumn{5}{|c|}{100} & 100 \\
\hline
\end{tabular}

Tabela 2. Valores da tabulação de degradação e IPE em porcentagem

\begin{tabular}{|l|r|r|r|r|}
\hline \multirow{5}{*}{ Valores da tabulação de degradação e IPE em porcentagem } \\
\cline { 2 - 5 } Degradação (\%) & \multicolumn{5}{|c|}{ Valores de IPE } \\
\hline Baixa degradação & $4953-4966$ & $4966-4975$ & $4975-4994$ & $4994-5033$ \\
\hline Média degradação & 30,3 & 22,1 & 26,8 & 45,0 \\
\hline Media alta degradação & 25,5 & 17,3 & 31,5 & 27,4 \\
\hline Alta degradação & 26,0 & 38,5 & 24,1 & 19,7 \\
\hline Total & 18,2 & 22,1 & 17,6 & 7,9 \\
\hline
\end{tabular}

A relação dos indicadores com a degradação mostra que os municípios com maiores porcentagem de alta degradação, que são Novo Triunfo, Pedro Alexandre e Glória, possuem os menores indicadores socioeconômicos, como acontece de maneira clara com o IPS que estão nos valores entre $4927-4950$ e a porcentagem de alta degradação é de $27 \%$, fato que mostra a redução da área com alta degradação conforme o aumento dos valores do índice.

A porcentagem de alta degradação de $22,1 \%$ está mais presente nos municípios de Uauá e Jeremoabo, com IPE entre 4966-4975, e uma concentração maior de baixa degradação com 45\% para os valores mais altos entre 4994-5033 dos municípios de Paulo Afonso e Rodelas. O aspecto econôtmico deixa claro a fragilidade dos municípios quanto à desertificação, principalmente para os que têm a base da economia nas atividades agrícola e pastoril.

Segundo Vasconcelos e Matallo "dois tipos de custos estão envolvidos na avaliação dos impactos econômicos da desertificação. O primeiro diz respeito às perdas econômicas resultantes da degradação de terras e, por conseguinte, da sua capacidade produtiva, e o segundo são os custos de controle e recuperação desses processos (que pode ser estimado a partir dos custos de reposição do meio ambiente ao seu estágio natural)".

Os munícipios que estão em áreas suscetíveis à desertificação, os elementos sociais e econômicos podem ser uma causa desse processo, mas também trazer consequências que vão influencia direto e indiretamente estes indicadores.

\section{CONCLUSÃO}

A desertificação está estritamente ligada ao meio natural, mas não se pode compreendê-la sem levar em conta fatores sociais e econômicos, que também são indicadores para a degradação. A dinâmica da sociedade pode causar a desertificação e está sujeita as consequências, portanto a desertificação não é somente um fenômeno físico e biológico que altera a paisagem, mas também social e econômico. 


\section{REFERÊNCIAS}

ACCILY, Luciano J. de O.; OLIVEIRA, Maria Aparecida J. de. Indicadores de processo de desertificação. In. Romeiro, Ademar Ribeiro. Avaliação e contabilização de impactos ambientais. Campina - SP: Editora da Unicamp, 2004.

BRASIL, Ministério do Meio Ambiente. PAN Brasil. Programa Nacional de Combate à Desertificação e Mitigação dos Efeitos da Seca. Brasília: Ministério do Meio Ambiente; Secretaria de Recursos Hídricos, 2004. Disponível em:< Http://www.mma.gov.br/estruturas/sedr_desertif/_arquivos/pan_brasil_portugues.pdf >. Acessado em: 20 agosto de 2013.

INSTITUTO BRASILEIRO DE GEOGRAFIA E ESTÁTISCA (IBGE). Índices de malha de malhas digitais, 2010. Disponível em: <ftp://geoftp.ibge.gov.br/malhas_digitais/censo_2010/setores_censitarios/>. Acessado em: novembro de 2013.

ÍNDICES DE PERFORMANCE ECONÔMICA E SOCIAL DA BAHIA. Salvador: Publicações da SEI, v.1, maio de 2013. Disponível em: $<$ http://www.sei.ba.gov.br/images/indicadores_especiais/pdf/ipe_ips/analise_dos_resultados.p df $>$. Acessado em: 21 de agosto de 2015.

OLIVEIRA JUNIOR, Israel de. O processo de desertificação: a vulnerabilidade e degradação ambiental no Polo Regional de Jeremoabo. 2014, 273 f. Tese (Dissertação em Geografia). Universidade Federal da Bahia, Salvador, Bahia, 2014.

JUNIOR, Heitor Matallo. Indicadores de desertificação: histórico e perspectivas. Brasília: UNESCO, 2001.

Miranda, J. I. Fundamentos de sistemas de informações geográficas. Brasília, DF: EMBRAPA Informação Tecnológica, 2005. 425p

Programa de Ação Estadual de Combate à Desertificação e Mitigação dos Efeitos da Seca do Estado da Bahia (PAE-BA), 2014.

RÊGO, André Heráclio do. Os sertões e os desertos: o combate à desertificação e a política externa brasileira. Brasilia: FUNAG, 2012. Disponível em: <http://www.funag.gov.br/biblioteca/dmdocuments/OS_SERTOES_E_OS_DESERTOS.pdf> . Acessado em: 10 de out. 2013. 